\title{
PRONE TRACHEAL INTUBATION SIMPLIFIED USING AN AIRWAY INTUBATOR
}

\author{
R.T. WILLIAMS AND R.E. HARRISON
}

\begin{abstract}
A new device which can be used as an oral airway or as an aid for blind oral intubation of the trachea is described. A case report describing the use of the device during intubation of a patient in the prone position is presented.
\end{abstract}

Key Words: ANAESTHesia EquipMEnT, airway intubator; INTUBation, tracheal, prone position.

THE ART of establishing a safe, clear airway in difficult circumstances continues to tax the ingenuity of the anaesthetist. Often it is a physical abnormality in the patient which causes the problem, sometimes the patient must be anaesthetised in an unusual position. When direct laryngoscopy is not possible or does not allow a view of the larynx blind intubation, either oral or nasal, may be used. Various techniques have been described.

Magill and Rowbotham perfected blind nasal intubation after it had been re-introduced during World War I. McKesson and Clement were also advocates of the blind technique using nitrous oxide-oxygen anaesthesia.'.

Tactile blind oral intubation ${ }^{2}$ has also been described but is fraught with danger for both anaesthetist and patient. In 1937 a divided metal airway with a locking nut was described, ${ }^{3}$ but it was not generally accepted, probably because of its low success rate and because its metal structure tended to cause damage to the oral cavity. In 1977 Berman ${ }^{4}$ described a plastic airway and suggested its use for intubating either the trachea or the oesophagus. Fibre-optics have increased the sophistication of equipment for laryngoscopy, but fibre-optic laryngoscopes are expensive and therefore not readily available and, in addition, considerable practice is required in using this equipment.

One of us (R.T.W.) has designed an "Airway Intubator". This serves as an oral airway through which a tracheal tube may be passed into the trachea. The following case report illustrates how useful this device can be in an unusual situation.

R.T. Williams, M.R.C.S., L.R.C.P., F.R.C.P.(C), Staff Anaesthetists; R.E. Harrison, M.D., Chief Resident; Department of Anaesthesia, Foothills Hospital, 1403-29th Street N.W., Calgary, Alberta, T2N 2T9.

\section{CASE Report}

A 27 year old man was admitted to hospital in July 1980 with 70 per cent burns to his face, trunk and limbs. Twenty-three days later he was brought to the operating room for extensive debridement and skin grafting. No premedication had been given and, to avoid turning the patient onto his back, the surgeon requested that the patient be anaesthetized prone on the Stryker frame and then positioned on the operating table, still in the prone position.

A slightly unorthodox approach had to be taken in inserting a percutaneous internal jugular catheter, with the anaesthetist kneeling on the floor and working upwards. Following this the patient was given diazepam $7.5 \mathrm{mg}$ and fentanyl $100 \mu \mathrm{g}$ intravenously. His tongue and pharynx were sprayed with 10 per cent lidocaine aerosol until an oral airway, pre-coated with two per cent lidocaine jelly on its lingual surface, could be inserted into his mouth without objection. The airway was then removed and the nozzle of the lidocaine aerosol was inserted down to the distal end of the airway so as to direct the spray onto the larynx (Figure 1).

Following re-insertion of the airway several sprays during inspiration assured that the patient's vocal cords and trachea were well anaesthetized. A total dose of about $110 \mathrm{mg}$ of lidocaine was used. While the patient was still awake, the oral airway was replaced by the "Airway Intubator". Through this a $7.0 \mathrm{~mm}$ tracheal tube ('Endotrol,' National Catheter Company) was guided easily into the trachea without additional aid.

Following tracheal intubation, anaesthesia was induced with thiopentone $100 \mathrm{mg}$ intravenously and the patient was transferred to the operating table. Anaesthesia was maintained with oxygen, nitrous oxide and enflurane with mechanical 


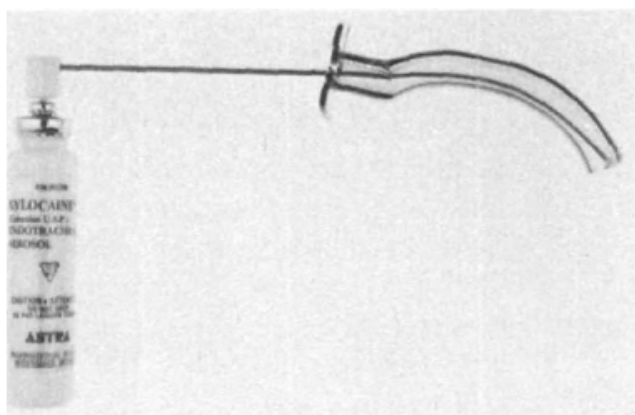

FIGURE 1 Lidocaine spray in the airway.

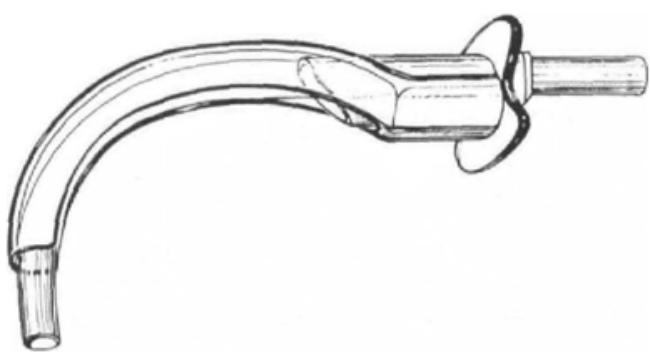

Figure 2 Diagram of airway intubator.

ventilation through a semiclosed circle system. At the end of the surgical procedure the patient was replaced on the Stryker frame, spontaneous 'ventilation was re-established and the tracheal tube was removed from the trachea but left in the airway intubator to serve as an oropharyngeal airway.

\section{DESCRIPTION}

The airway intubator (Figure 2), not at present available commercially, was fashioned out of a Portex Guedel type airway $(9 \mathrm{~cm})$. The proximal half is in the shape of a cylindrical tunnel and the distal half is open on its lingual surface to permit the passage of a tracheal tube (Figure 3).

\section{Discussion}

The "Airway Intubator", although still a prototype, has been used more than 300 times. Even in non-medical hands, (dentists, paramedics, nurses and dental assistants), the success rate for tracheal intubations has been about 80 per cent. The instrument is lightweight, easy to use and requires no electrical supply. Thus many of the

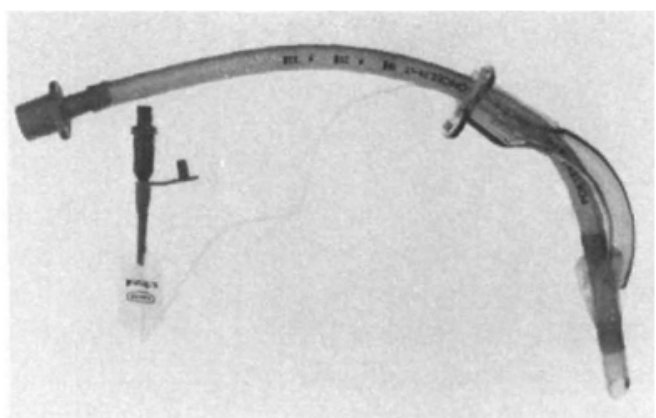

Figure 3 Tracheal tube inside airway intubator.

limitations of the laryngoscope are overcome. Therefore the "Airway Intubator" may be used in situations when neither a laryngoscope nor a person experienced in laryngoscopy is immediately available. Other advantages of the device are that its use by someone with limited experience is unlikely to damage the teeth; once in place it will allow suctioning of the airway with a wide bore suction catheter and, if a tracheal tube is inserted, it will protect the tube from occlusion by the patient's teeth.

The "Airway Intubator" differs from the intubating devices described by Sykes and Berman in that they were tubular, whereas the "Airway Intubator" is only tubular in its proximal half and this serves as a splint; the distal half of the intubator which is open on its lingual surface serves as a guide for the tracheal tube, thus taking advantage of presently available plastic tracheal tubes. The curve and relative firmness of the tracheal tube contributes significantly to the success of the technique described.

\section{REFERENCES}

1. ELder, C.K. Naso-endotracheal Intubation: Advantages and Techniques of "Blind Intubation", Anesthesiology $5: 392,1944$.

2. Collins, V.J. Principles of Anesthesiology 2nd Ed. Lea \& Febiger, 1976.

3. SYKES, W.S. Oral Endotracheal Intubation Without Laryngoscopy: A Plea for Simplicity Anesth. Anal. 16: 133-136, 1937.

4. BERMAN, R A. A Method of Blind Oral Intubation of the Trachea or Esophagus Anesth. Anal. 56: 866-867, 1977

5. WILLIAMS, R.T. (in press)

Les auteurs décrivent une nouvelle canule pouvant à la fois servir de canule oro-pharingée ou de guide pour une intubation oro-trachéale à l'aveugle. En guise d'illustration ils rapportent le cas d'un malade qu'ils durent intuber en position ventrale et chez lequel cette innovation a facilité une intubation à l'aveugle. 